\title{
Исследование состава фрлавоноидов плодов облепихи крушиновидной
}

\author{
Тринеева О.В. ${ }^{1}$, Перова И.Б. ${ }^{2}$, Сливкин А.И. ${ }^{1}$, Эллер К.И. ${ }^{2}$ \\ ${ }^{I}$ ФГБОУ ВО «Воронежский государственный университет», Воронеж \\ ${ }^{2}$ ФГБУН «ФИЦ питания и биотехнологии», Москва
}

Поступила в редакцию 13.09.2016 г.

Проведено исследование содержания и профиля флавоноидов плодов облепихи крушиновидной (Hippophae rhamnoides L.) с помощью метода ВЭЖХ-ДМД-МС, TCX и дифференциальной спектрофотометрии. В плодах облепихи обнаружены флавонолгликозиды - производные кверцетина, кемпферола и изорамнетина. В плодах облепихи впервые идентифицирован кверцетин-3-рутинозид7-глюкуронид .

Ключевые слова: профиль флавоноидов, плоды облепихи крушиновидной, ТСХ, ВЭЖХ с диодно-матричным и масс-селективным детекторами.

\section{Study the composition of flavonoids fruits of sea buckthorn}

\author{
Trineeva O.V. ${ }^{1}$, Perova I.B. ${ }^{2}$, Slivkin A.I. ${ }^{1}$, Eller K.I. ${ }^{2}$ \\ ${ }^{I}$ Voronezh state university, Voronezh \\ ${ }^{2}$ Federal Research Centre of Nutrition and Biotechnology, Moscow
}

Wild plants attract the attention of researchers because of their prospects in the manufacture of a medicament of a wide spectrum of action. They are a rich source of biologically active substances such as flavonoids, derivatives dihydroxycoriches acids, iridoids, and other carotenoids. Fruits of sea buckthorn studied in detail as a source of carotenoids and fatty oils. At the same time, relatively little is known about the content and composition of flavonoids in fresh and dried fruit of sea buckthorn, which does not allow to evaluate the contribution of this class of biologically active substances in the total biological activity of preparations based on fruit sea buckthorn.

The content and profile of flavonoids of sea buckthorn fruits was investigated by using HPLC-DADMS/TOF, TLC and differential spectrophotometry. The flavonolglycosides derivatives of quercetin, kaempferol and isorhamnetin were found as the main flavonoids of sea buckthorn . The quercetin-3-rutinoside-7glucuronide was identified in sea buckthorn fruits for the first time. tectors, TLC.

Keywords: profile of flavonoids, sea buckthorn fruit, HPLC with diode array and mass selective de-

\section{Введение}

Дикорастущие растения привлекают внимание исследователей вследствие их перспективности в получении лекарственных препаратов широкого спектра действия. Они являются богатым источником биологически активных веществ (БАВ), таких как флавоноиды, производные дигидроксикоричных кислот, иридоды, каротиноиды и др. Плоды облепихи крушиновидной подробно изучены в качестве источ- 
ника каротиноидов и жирного масла [1-3]. В то же время относительно мало известно о содержании и составе флавоноидов как в свежих, так и высушенных плодах облепихи, что не позволяет оценить вклад этого класса БАВ в общую биологическую активность препаратов на основе плодов Hippophae rhamnoides.

Цель настоящей работы - подробное исследование состава и концентрации различных групп флавоноидов плодов облепихи крушиновидной.

\section{Эксперимент}

Объектом исследования служили высушенные плоды облепихи крушиновидной Hippophae rhamnoides, собранные в Воронежской области согласно правилам заготовки лекарственного растительного сырья (ЛРС). Сушку плодов проводили при температуре не выше $60^{\circ} \mathrm{C}$ до остаточной влажности не более $14 \%$.

Стандарты и растворители. В качестве стандартных образцов использовались коммерчески доступные индивидуальные вещества: рутин ( $\geq 94 \%$, Sigma), гиперозид ( $\geq 95 \%$, HWI ANALYTIK GMBH), изокверцитрин ( $\geq 94 \%$, HWI ANALYTIK GMBH), кемпферол-3-глюкозид ( $\geq 95 \%$, PhytoLab). В работе были использованы следующие растворители/реактивы: вода очищенная (получена с помощью системы MilliQ ${ }^{\circledR}$ Advantage A10), ацетонитрил UPLC/HPLC grade производства AppliChem PanReac (Дармштадт, Германия), метанол UPLC/HPLC grade производства J.T. Baker (Avantor Performance Materials, Пало Альто, США), муравьиная кислота 98-100\% производства Merck (Дармштадт, Германия), алюминия хлорид шестиводный, ледяная уксусная кислота, н-бутанол, этилацетат марок х.ч. и ч.д.а. (ЗАО «Вектон», СПб, Россия).

Методы исследования. Качественный анализ на присутствие флавоноидов проводили методом ТСХ по разработанной ранее методике [4,5].

Для количественного определения суммы флавоноидов в пересчете на рутин в плодах облепихи крушиновидной была использована ранее разработанная методика с использованием дифференциальной спектрофотометрии (СФМ) [6].

Состав и концентрацию индивидуальных флавоноидов определяли с помощью ВЭЖХ с диодно-матричным (ДМД) и масс-селективным детекторами (МС) [7].

Пробоподготовка. Для исследования профиля флавоноидов около 2.0 г (точная навеска) измельченного сырья переносили в круглодонную колбу на $100 \mathrm{~cm}^{3}$, добавляли $50 \mathrm{~cm}^{3} 60 \%$ метанола. Экстракцию проводили на водяной бане с обратным холодильником при температуре $95^{\circ} \mathrm{C}$ в течение 1 ч. Далее колбу с извлечением охлаждали до комнатной температуры и помещали на ультразвуковую баню на 5 мин. Содержимое колбы переносили в мерную колбу вместимостью $50 \mathrm{~cm}^{3}$, доводили до метки $60 \%$ метанолом, аликвоту в $1.5 \mathrm{~cm}^{3}$ переносили в центрифужную пробирку и центрифугировали при 15000 об/мин в течение 5 мин. Супернатант помещали в виалу для автосемплера.

ВЭЖХ исследования проводились с использованием системы Agilent 1100 (Agilent Technologies, CША), оснащенной бинарным насосом, дегазатором, термостатируемым автосемплером, термостатом колонок, ДМД спектрофотометрическим (Agilent 1100 Series Diode Array) и времяпролетным (TOF) MC-детектором (Agilent $6200 \mathrm{TOF}$ LC/MS). Идентификацию и определение содержания флавоноидов проводили по методике, разработанной ранее для анализа данных групп БАВ [7]. Условия ВЭЖХ. Неподвижная фаза: колонка ProteCol C18 HPH125 250×4.6 мм с размером частиц $5 \mu$. Подвижная фаза: А - $0.1 \%$ раствор муравьиной кислоты, В - ацетонитрил. Градиентное элюирование 0-40 мин, 10-60\% В, затем регенерация колонки 4150 мин, $10 \%$ В. Температура колонки $30^{\circ} \mathrm{C}$, температура автосемплера $20^{\circ} \mathrm{C}$, скорость

Tринеева и др. / Сорбционные и хроматографические процессы. 2017. Т. 17. № 1 
подачи элюента $0.5 \mathrm{~cm}^{3} /$ мин, объем вводимой пробы 10 нл. Спектрофотометрическое детектирование проводилось при 5 аналитических длинах волн: 370 нм, 350 нм, 338 нм, 330 нм и 290 нм. Условия масс-детектирования. Ионизация электроспреем, сканирование масс - в режиме регистрации положительных ионов (ESI-MS ${ }^{+}$) в диапазоне m/z 100-1000 Да. Рабочие параметры источника ионизации: напряжение на капилляре $3500 \mathrm{~B}$, поток газа-осушителя (азот) 9 л/мин, температура $325^{\circ} \mathrm{C}$, давление на распылителе 0,27 МПа. Напряжение на фрагменторе 175 В, на конусе - 65 В, на октополе ОСТ 1RF Vpp - 250 В. Обработка данных осуществлялась с помощью программного обеспечения Agilent MassHunter Workstation Software. Содержание флавоноидов оценивали методом внешнего стандарта по формуле:

$$
X, \text { мг / }=\frac{S_{\text {фаив }} \cdot C_{\text {станд }} \cdot 50 \cdot 1000}{S_{\text {станд }} \cdot m_{\text {навески }}},
$$

где $\mathrm{S}_{\text {флав }}$ - площадь пика флавоноида в извлечении из плодов облепихи; $\mathrm{S}_{\text {станд }}-$ площади пика стандарта флавоноида; $\mathrm{C}_{\text {станд }}$ - концентрация стандарта флавоноида, мг $/ \mathrm{cm}^{3} ; 50$ - объем разведения извлечения из плодов облепихи, $\mathrm{cm}^{3} ; \mathrm{m}_{\text {навески }}$ масса навески измельченных плодов облепихи, мг; 1000 - коэффициент для пересчета на $1 г$.

\section{Обсуждение результатов}

На хроматограммах извлечения из плодов облепихи в УФ-свете после проявления $5 \%$ спиртовым раствором $\mathrm{NaOH}$ наблюдали 7 зон. При сравнении величин $\mathrm{R}_{\mathrm{f}}$ полученных хроматографических зон со стандартными образцами, были идентифицированы зоны рутина $\left(\mathrm{R}_{\mathrm{f}}=0.53 \pm 0.02\right)$ и кверцетина $\left(\mathrm{R}_{\mathrm{f}}=0.80 \pm 0.02\right)$. Неидентифицированные зоны предположительно относятся к флавоноидам, так как имеют характерное свечение в УФ-свете.

Результаты спектрофотометрического определения суммы флавоноидов в пересчёте на рутин в плодах облепихи крушиновидной и статистическая обработка данных приведены в таблице 1.

Таблица 1. Метрологическая характеристика результатов определения суммы флавоноидов в пересчете на рутин (\%) методом СФМ* $(\mathrm{P}=95 \% ; \mathrm{n}=4)$

\begin{tabular}{|c|c|c|c|c|c|c|c|c|}
\hline $\mathrm{f}$ & $\mathrm{x}_{\mathrm{cp}} \%$ & $\mathrm{~S}^{2}$ & $\mathrm{~S}$ & $\mathrm{Sx}_{\mathrm{cp}}$ & $\mathrm{t}(\mathrm{P}, \mathrm{t})$ & $\Delta \mathrm{x}$ & $\Delta \mathrm{x}_{\mathrm{cp}}$ & $\varepsilon_{\mathrm{cp}}, \%$ \\
\hline 3 & 0.5500 & 0.00577 & 0.0759 & 0.03795 & 3.18 & 0.24 & 0.0612 & 11.13 \\
\hline
\end{tabular}
*3десь и далее в пересчете на абсолютно сухое сырье

В плодах облепихи методом ВЭЖХ-ДМД-МС обнаружены флавонолгликозиды - производные кверцетина, кемпферола и изорамнетина, основными из которых были изорамнетин-3-рутинозид (18.2\% от суммы флавоноиов), изорамнетин-3софорозид-7-рамнозид $(13.1 \%)$ и изорамнетин-3-глюкозид-7-рамнозид $(12.6 \%)$ (рис. 1). Коэффициенты емкости, результаты масс-спектрометрического анализа, максимумы поглощения и содержание флавоноидов облепихи представлены в таблице 2. Спектр поглощения преобладающего в исследуемых плодах облепихи флавоноида - изорамнетин-3-рутинозида представлен на рисунке 2.

Суммарное содержание флавоноидов в плодах облепихи крушиновидной составило 2.25 мг/г. Среди минорных соединений идентифицированы 3-рутинозид-7рамнозиды изорамнетина, кверцетина и кемпферола, 3-софорозид-7-рамнозиды кверцетина и кемпферола, рутин, 3-глюкозид и 3-рамнозид изорамнетина. Полученные результаты соответствуют литературным данным о профиле флавоноидов обле-

Tринеева и др. / Сорбционные и хроматографические процессы. 2017. Т. 17. № 1 
пихи крушиновидной. В ряде исследований [8-10] среди препаративно-выделенных из плодов и листьев облепихи флавоноидов методом ${ }^{1} \mathrm{H}$ и ${ }^{13} \mathrm{C}$ ЯМР-спектроскопии идентифицированы 7-O- $\alpha$-L-рамнозиды изорамнетина, кверцетина и кемпферола, имеющие различные гликозидные остатки в положении С-3, преимущественно софорозиды, рутинозиды и глюкозиды. Присутствие в облепихе кверцетин-3рутинозид-7-глюкуронида отмечено нами впервые.

Таблица 2. Результаты ВЭЖХ-ДМД-МС анализа профиля флавоноидов в плодах облепихи крушиновидной

\begin{tabular}{|c|c|c|c|c|c|c|}
\hline № & Флавоноид & $\mathrm{K}^{*}$ & $\begin{array}{c}\text { ESI- } \\
\mathrm{MS}^{+}, \mathrm{m} / \mathrm{z}\end{array}$ & Детектируемый ион & $\begin{array}{c}\lambda_{\max }, \\
\mathrm{HM}\end{array}$ & $\begin{array}{l}\text { Со- } \\
\text { дер } \\
\text { жа- } \\
\text { ние, } \\
\text { мг/Г }\end{array}$ \\
\hline 1 & 2 & 3 & 4 & 5 & 6 & 7 \\
\hline 1 & $\begin{array}{c}\text { Кверцетин-3- } \\
\text { софорозид-7- } \\
\text { рамнозид, } \\
\text { Сирингетин-гликозид }\end{array}$ & 2.95 & $\begin{array}{l}773.27 \\
611.21 \\
449.16, \\
333.18, \\
303.17\end{array}$ & $\begin{array}{c}{[\mathrm{M}+\mathrm{H}]^{+}} \\
{[\mathrm{M}-\text { глюкоза** + H }]^{+}} \\
{[\mathrm{M}-\text { софороза }+\mathrm{H}]^{+}} \\
{[\mathrm{M}-\text { гликозид }+\mathrm{H}]^{+}} \\
{[\mathrm{M}-\text { софороза }- \text { рамноза }+} \\
\mathrm{H}]^{+}\end{array}$ & $\begin{array}{l}256, \\
266, \\
354\end{array}$ & 0.21 \\
\hline 2 & $\begin{array}{c}\text { Кверцетин-3- } \\
\text { рутинозид-7-рамнозид }\end{array}$ & 3.14 & $\begin{array}{l}757.28 \\
303.17\end{array}$ & $\begin{array}{c}{[\mathrm{M}+\mathrm{H}]^{+}} \\
{[\mathrm{M}-\text { pутиноза }- \text { рамноза }+} \\
\mathrm{H}]^{+}\end{array}$ & $\begin{array}{l}258, \\
266, \\
360\end{array}$ & 0.14 \\
\hline 3 & $\begin{array}{c}\text { Кемпферол-3- } \\
\text { софорозид-7-рамнозид }\end{array}$ & 3.19 & $\begin{array}{l}757.28 \\
595.22 \\
433.16 \\
287.09\end{array}$ & $\begin{array}{c}{[\mathrm{M}+\mathrm{H}]^{+}} \\
{[\mathrm{M}-\text { глюкоза }+\mathrm{H}]^{+}} \\
{[\mathrm{M}-\text { софороза }+\mathrm{H}]^{+}} \\
{[\mathrm{M}-\text { софороза }- \text { рамноза }+} \\
\mathrm{H}]^{+} \\
\end{array}$ & $\begin{array}{l}266, \\
346\end{array}$ & 0.15 \\
\hline 4 & $\begin{array}{l}\text { Кверцетин-3- } \\
\text { рутинозид-7- } \\
\text { глюкуронид }\end{array}$ & 3.22 & $\begin{array}{l}787.29 \\
641.23 \\
479.17 \\
303.17\end{array}$ & $\begin{array}{c}{[\mathrm{M}+\mathrm{H}]^{+}} \\
{[\mathrm{M}-\text { рамноза }+\mathrm{H}]^{+}} \\
{[\mathrm{M}-\text { рутиноза }+\mathrm{H}]^{+}} \\
{[\mathrm{M}-\text { рутиноза }- \text { глюкур. к- }} \\
\text { та }+\mathrm{H}]^{+} \\
\end{array}$ & $\begin{array}{l}254, \\
266, \\
352\end{array}$ & 0.17 \\
\hline 5 & $\begin{array}{c}\text { Изорамнетин-3- } \\
\text { софорозид-7-рамнозид }\end{array}$ & 3.29 & $\begin{array}{l}787.29 \\
625.23 \\
463.17 \\
317.10\end{array}$ & $\begin{array}{c}{[\mathrm{M}+\mathrm{H}]^{+}} \\
{[\mathrm{M}-\text { глюкоза }+\mathrm{H}]^{+}} \\
{[\mathrm{M}-\text { софороза }+\mathrm{H}]^{+}} \\
{[\mathrm{M}-\text { софороза }- \text { рамноза }+} \\
\mathrm{H}]^{+}\end{array}$ & $\begin{array}{l}254, \\
266, \\
352\end{array}$ & 0.30 \\
\hline 6 & $\begin{array}{c}\text { Изорамнетин-3- } \\
\text { рутинозид-7-рамнозид }\end{array}$ & 4.12 & $\begin{array}{l}771.29 \\
625.23 \\
463.17 \\
317.10\end{array}$ & $\begin{array}{c}{[\mathrm{M}+\mathrm{H}]^{+}} \\
{[\mathrm{M}-\text { рамноза }+\mathrm{H}]^{+}} \\
{[\mathrm{M}-\text { рутиноза }+\mathrm{H}]^{+}} \\
{[\mathrm{M}-\text { рутиноза }- \text { рамноза }+} \\
\mathrm{H}]^{+}\end{array}$ & $\begin{array}{l}255, \\
270 \\
366\end{array}$ & 0.11 \\
\hline 7 & $\begin{array}{c}\text { Неидентифицирован- } \\
\text { ный флавонолгликозид }\end{array}$ & 4.17 & $\begin{array}{l}741.28 \\
595.22\end{array}$ & (2) & $\begin{array}{l}254, \\
266, \\
358\end{array}$ & 0.12 \\
\hline 8 & $\begin{array}{c}\text { Изорамнетин-3- } \\
\text { глюкозид-7-рамнозид }\end{array}$ & 4.22 & $\begin{array}{l}625.23 \\
463.17 \\
317.10\end{array}$ & $\begin{array}{c}{[\mathrm{M}+\mathrm{H}]^{+}} \\
{[\mathrm{M}-\text { глюкоза }+\mathrm{H}]^{+}} \\
{[\mathrm{M}-\text { глюкоза }- \text { рамноза }+} \\
\mathrm{H}]^{+}\end{array}$ & $\begin{array}{l}254, \\
266, \\
352\end{array}$ & 0.28 \\
\hline 9 & Рутин & 4.50 & $\begin{array}{l}611.21 \\
465.15 \\
303.09\end{array}$ & $\begin{array}{c}{[\mathrm{M}+\mathrm{H}]^{+}} \\
{[\mathrm{M}-\text { рамноза }+\mathrm{H}]^{+}} \\
{[\mathrm{M}-\text { рутиноза }+\mathrm{H}]^{+}}\end{array}$ & $\begin{array}{l}256, \\
266, \\
356\end{array}$ & 0.14 \\
\hline
\end{tabular}




\begin{tabular}{|c|c|c|c|c|c|c|}
\hline 1 & 2 & 3 & 4 & 5 & 6 & 7 \\
\hline 10 & $\begin{array}{c}\text { Изорамнетин-3- } \\
\text { рутинозид }\end{array}$ & 5.06 & $\begin{array}{l}625.23, \\
479.17 \\
317.10\end{array}$ & $\begin{array}{c}{[\mathrm{M}+\mathrm{H}]^{+}} \\
{[\mathrm{M}-\text { рамноза }+\mathrm{H}]^{+}} \\
{[\mathrm{M}-\text { рутиноза }+\mathrm{H}]^{+}}\end{array}$ & $\begin{array}{l}254, \\
266, \\
356\end{array}$ & 0.41 \\
\hline 11 & $\begin{array}{c}\text { Изорамнетин-3- } \\
\text { глюкозид }\end{array}$ & 5.44 & $\begin{array}{l}479.17 \\
317.10\end{array}$ & $\begin{array}{c}{[\mathrm{M}+\mathrm{H}]^{+}} \\
{[\mathrm{M}-\text { глюкоза }+\mathrm{H}]^{+}}\end{array}$ & $\begin{array}{l}254, \\
266, \\
356\end{array}$ & 0.14 \\
\hline 12 & $\begin{array}{c}\text { Изорамнетин-3- } \\
\text { рамнозид }\end{array}$ & 7.12 & $\begin{array}{l}463.17 \\
317.10\end{array}$ & $\begin{array}{c}{[\mathrm{M}+\mathrm{H}]^{+}} \\
{[\mathrm{M}-\text { рамноза }+\mathrm{H}]^{+}}\end{array}$ & $\begin{array}{l}254, \\
270, \\
370\end{array}$ & 0.06 \\
\hline 13 & Изорамнетин & 8.84 & 317.10 & {$[\mathrm{M}+\mathrm{H}]^{+}$} & $\begin{array}{l}254, \\
270, \\
372\end{array}$ & 0.02 \\
\hline \multicolumn{6}{|c|}{ Сумма флавоноидов } & 2.25 \\
\hline
\end{tabular}

*Коэффициент емкости; **Гликозидный остаток, представляющий собой молекулярную массу минус 18 Да (молекула воды, теряющаяся при образовании гликозидной связи).

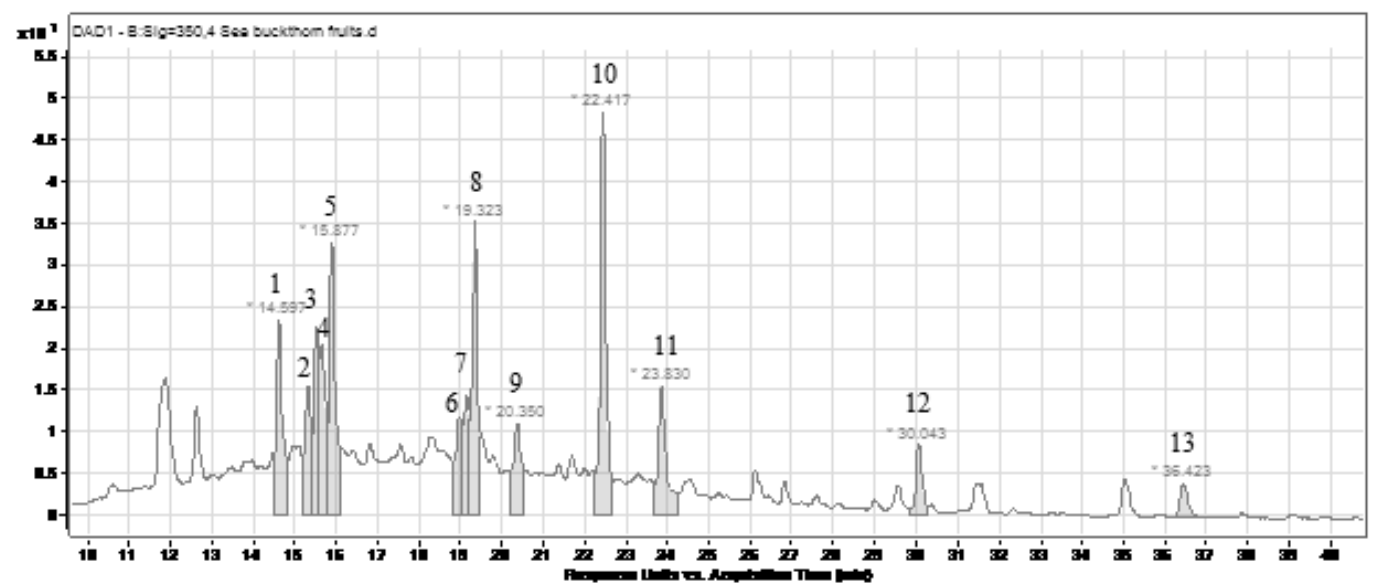

Рис. 1. Хроматограмма извлечения из плодов облепихи крушиновидной при $\lambda=350$ нм. Номера пиков флавоноидов на хроматограмме соответствуют номерам в таблице 2.

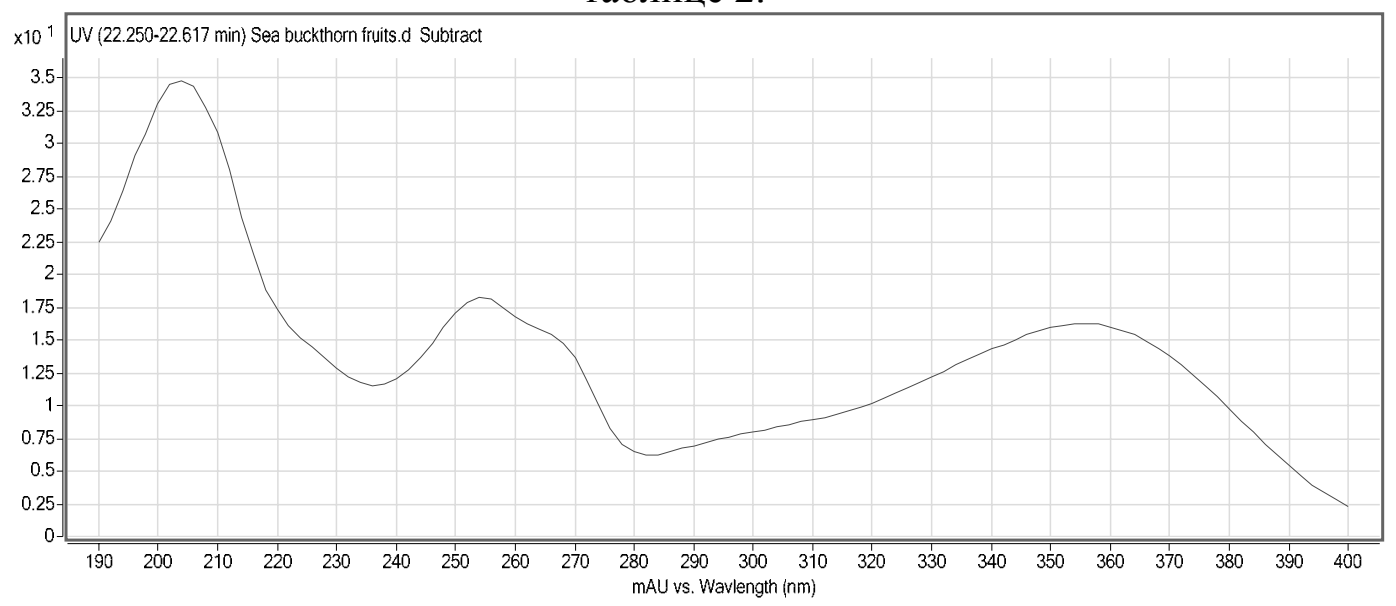

Рис. 2. Спектр поглощения изорамнетин-3-рутинозида

\section{Заключение}

Проведено исследование содержания и профиля флавоноидов плодов облепихи крушиновидной. Предварительная идентификация с помощью ТСХ-анализа пока- 
зала наличие в плодах облепихи рутина и кверцетина, что подтверждено методом ВЭЖХ-ДМД-МС. Данные о количественном содержании флавоноидов в объекте исследования, полученные неселективным методом СФМ и методом ВЭЖХ-ДМД-МС, различались приблизительно в два раза. Целесообразно в дальнейшем проведение дополнительного исследования для оценки корреляции результатов упрощенного СФМ метода с результатами прямого определения индивидуальных флавоноидов методом ВЭЖХ-ДМД-МС.

\section{Список литературы}

1. Тринеева О.В., Сливкин А.И. // Вестник ВГУ. Серия: Химия. Биология. Фармаџия. 2016. № 2. C. 145-151.

2. Тринеева О.В. // Международная конференция "Актуальные вопросы медицины в современных условиях». - СПб, 14 янв. 2015. C. 197-200.

3. Тринеева О.В., Сливкин А.И. // Сорбичионные и хроматографические прочессы. 2016. T.16. №2. C. 212-219.

4. Тринеева О.В., Сафонова И.И., Сафонова Е.Ф., Сливкин А.И. // Сорбичионыье и хроматографические проиессы. 2012. Т. 12. № 5. C. 806-813.

5. Чечета О.В., Сливкин А.И., Сафонова И.И. // Всероссийская с международным участием научно-методическая конференичи «Пути и формы совершенствования

\section{References}

1. Trineeva O.V., Slivkin A.I., Vestnik VGU. Serija: Himija. Biologija. Farmacija, 2016, No 2, pp. 145-151.

2. Trineeva O.V., Mezhdunarodnaja konferencija "Aktual'nye voprosy mediciny $\mathrm{v}$ sovremennyh uslovijah», SPb, 14 janv. 2015, pp. 197-200.

3. Trineeva O.V., Slivkin A.I., Sorbtsionnye $i$ khromatograficheskie protsessy, 2016, Vol. 16, No 2, pp. 212-219.

4. Trineeva O.V., Safonova I.I., Safonova E.F., Slivkin A.I., Sorbtsionnye i khromatograficheskie protsessy, 2012, Vol. 12, No 5, pp. 806-813.

5. Checheta O.V., Slivkin A.I., Safonova I.I., Vserossijskaja s mezhdunarodnym uchastiem nauchno-metodicheskaja konferencija «Puti $i$ formy sovershenstvovanija farma- фармацевтического образования. Поиск новых физиологически активных веществ «Фармобразование-2010». С. 407-410.

6. Тринеева О.В., Сафонова И.И., Сафонова Е.Ф., Сливкин А.И. // Фармация. 2012. № 7. C. $18-21$.

7. Жогова А.А., Перова И.Б., Самылина И.А. и др. // Химико-фармачевтический журнал. 2014. Т. 48. №7. С. 54-59.

8. Rösch D., Krumbein A., Mügge C., et al. // J. Agric. Food Chem. 2004. Vol. 52. Iss. 13. pp 4039-4046.

9. Gutzeit D., Wray V., Winterhalter P. et al. // Chromatographia. 2006. Vol. 65(1). No 12. pp. 1-7.

10.Arimboor R., Arumughan C. // International Journal of Food Sciences and Nutrition. 2012. Vol. 63. Iss. 6. pp. 730-738.

cevticheskogo obrazovanija. Poisk novyh fiziologicheski aktivnyh veshhestv «Farmobrazovanie-2010», pp. 407-410.

6. Trineeva O.V., Safonova I.I., Safonova E.F., Slivkin A.I., Farmacija, 2012, No 7, pp. 18-21.

7. Zhogova A.A., Perova I.B., Samylina I.A. et al., Himiko-farmacevticheskij zhurnal, 2014, Vol. 48, No 7, pp. 54-59.

8. Rösch D., Krumbein A., Mügge C. et al., J. Agric. Food Chem., 2004, Vol. 52, Iss. 13, pp. 4039-4046.

9. Gutzeit D., Wray V., Winterhalter P. et al., Chromatographia, 2006, Vol. 65(1), No 12, pp. 1-7.

10.Arimboor R., Arumughan C., International Journal of Food Sciences and Nutrition. 2012, Vol. 63, Iss. 6, pp. 730-738. 
Тринеева Ольга Валерьевна - к.фарм..н., доцент кафедры фармацевтической химии и фармацевтической технологии фармацевтического факультета ВГУ, Воронеж

Перова Ирина Борисовна - к. фарм.н., младший научный сотрудник лаборатории метаболомного и протеомного анализа ФГБУН «ФИЦ питания и биотехнологии», Москва

Сливкин Алексей Иванович - д.фарм.н., профессор, зав. кафедрой фармацевтической химии и фармацевтической технологии, декан фармацевтического факультета ВГУ, Воронеж

Эллер Константин Исаакович - д.Х.н., профессор, заведующий лабораторией метаболомного и протеомного анализа ФГБУН «ФИЦ питания и биотехнологии», Москва
Trineeva Olga V. - candidate of pharmaceutical sciences, associate professor of pharmaceutical chemistry and pharmaceutical technology of pharmaceutical faculty of VGU, Voronezh,. e-mail: trineevaov@mail.ru.

Perova Irina B. - $\mathrm{PhD}$ (pharmaceutical sciences), researcher of the laboratory of metabolomic and proteomic analysis of the Federal Research Centre of Nutrition and Biotechnology, Moscow

Slivkin Alexey I. - doctor pharm. sciences, professor, manager. chair of pharmaceutical chemistry and pharmaceutical technology, dean of pharmaceutical faculty of VGU, Voronezh

Eller Konstantin I. - doctor of sciences (chemistry), professor, head of the laboratory of metabolomic and proteomic analysis of the Federal Research Centre of Nutrition and Biotechnology, Moscow 